\title{
Anticoagulant Synergism of Heparin and Activated Protein C In Vitro Role of a Novel Anticoagulant Mechanism of Heparin, Enhancement of Inactivation of Factor V by Activated Protein C
}

Jari Petäjä, José A. Fernández, András Gruber, and John H. Griffin

Department of Molecular and Experimental Medicine and Department of Vascular Biology, The Scripps Research Institute, La Jolla, California 92037

\begin{abstract}
Interactions between standard heparin and the physiological anticoagulant plasma protein, activated protein $\mathrm{C}$ (APC) were studied. The ability of heparin to prolong the activated partial thromboplastin time and the factor $\mathrm{Xa}-$ one-stage clotting time of normal plasma was markedly enhanced by addition of purified APC to the assays. Experiments using purified clotting factors showed that heparin enhanced by fourfold the phospholipid-dependent inactivation of factor V by APC. In contrast to factor V, there was no effect of heparin on inactivation of thrombin-activated factor Va by APC. Based on SDS-PAGE analysis, heparin enhanced the rate of proteolysis of factor $\mathrm{V}$ but not factor Va by APC. Coagulation assays using immunodepleted plasmas showed that the enhancement of heparin action by APC was independent of antithrombin III, heparin cofactor II, and protein S. Experiments using purified proteins showed that heparin did not inhibit factor $\mathrm{V}$ activation by thrombin. In summary, heparin and APC showed significant anticoagulant synergy in plasma due to three mechanisms that simultaneously decreased thrombin generation by the prothrombinase complex. These mechanisms include: first, heparin enhancement of antithrombin III-dependent inhibition of factor $\mathrm{V}$ activation by thrombin; second, the inactivation of membrane-bound FVa by APC; and third, the proteolytic inactivation of membrane-bound factor $\mathrm{V}$ by APC, which is enhanced by heparin. (J. Clin. Invest. 1997. 99:2655-2663.) Key words: anticoagulants • protein $\mathrm{C} \bullet$ factor $\mathrm{V} \cdot$ factor $\mathrm{Va} \cdot$ antithrombin III
\end{abstract}

\section{Introduction}

Heparin is one of the most important drugs for the treatment and prevention of venous thrombosis. The anticoagulant functions of heparin include inhibition of thrombin, coagulation factors Xa, IXa, XIa, and XIIa as well as inhibition of platelet function (1-3). Antithrombin III (AT III) ${ }^{1}$ and heparin cofactor II (HC II) are major regulators of heparin but some antico-

The first two authors contributed equally to the studies in this paper. Address correspondence to Dr. John H. Griffin, Department of Molecular and Experimental Medicine, SBR-5, The Scripps Research Institute, 10550 North Torrey Pines Road, La Jolla, CA 92037. Phone: 619-784-8220; FAX: 619-784-2243; E-mail: jgriffin@ scripps.edu

Received for publication 11 October 1996 and accepted in revised form 11 March 1997.

J. Clin. Invest.

(C) The American Society for Clinical Investigation, Inc.

0021-9738/97/06/2655/09 \$2.00

Volume 99, Number 11, June 1997, 2655-2663 agulant functions of heparin are independent of both cofactors $(1,4,5)$. Whereas a large and growing body of knowledge exists of the complex biochemistry of heparin in hemostasis, it is clear that the known anticoagulant actions of heparin do not entirely explain all the antithrombotic properties of heparin in vivo. As a result, securing antithrombotic efficacy while avoiding bleeding complications remains a clinically relevant problem.

Little is known about the possible interactions of pharmacological anticoagulation by heparin and the anticoagulant protein C pathway. Activated protein C (APC) is a physiological anticoagulant whose importance is clearly demonstrated by the thrombotic diathesis associated with heterozygous or homozygous protein $\mathrm{C}$ deficiencies (6-8) or with resistance to activated protein $\mathrm{C}(9-16)$. If interactions between heparin and APC exist, they are likely significant for the understanding of the mechanism of action of heparin. Additionally, interaction between heparin and the protein $\mathrm{C}$ pathway could be clinically significant since purified protein $\mathrm{C}$ infusions have been used in clinical trials $(17,18)$. Heparin stimulates inhibition of APC by the plasma serine protease inhibitor, protein C inhibitor (19-21). However, such heparin-dependent inhibition of APC may not be important since therapeutic concentrations of heparin and physiologically relevant levels of APC synergistically prolong plasma clotting time (22). In addition to the known mechanisms for anticoagulant actions of heparin and APC, a novel anticoagulant mechanism of heparin is described here, namely enhancement of the proteolytic inactivation of membranebound blood coagulation factor $\mathrm{V}$ but not factor Va by APC.

\section{Methods}

Materials. Unfractionated standard porcine heparins for laboratory use were purchased from Sigma Chemical Co. (St. Louis, MO) and Celsus Inc. (Cincinnati, OH). Unfractionated heparin for clinical use was purchased from E.R. Squibb \& Sons Inc. (Princeton, NJ; Heparin sodium injection, 1,000 USP/ml). Factor $\mathrm{Xa}(\mathrm{FXa})$ and protein $\mathrm{S}$ were purchased from Enzyme Research Laboratories (South Bend, IN) and human antithrombin III (AT III) from Sigma Chemical Co. Prothrombin and single-chain factor $\mathrm{V}(\mathrm{FV})$ were purified as described (23). Protein $\mathrm{C}$ was purified and activated by thrombin-Sepharose into APC as described and the activity of APC was characterized by coagulation assays as described (24). Gln506-FV was purified as previously described (25). FV and Gln506-FV were consequently activated by thrombin as described (25). Prothrombin, FV, protein $\mathrm{C}$, and APC were greater than $95 \%$ pure by SDS-PAGE and were

1. Abbreviations used in this paper: APC, activated protein C; APTT, activated partial thromboplastin time; AT III, antithrombin III; FV, factor V; FVa, activated factor V; Gln506-FV, Arginine 506 to Glutamine mutated FV; FVIII, factor VIII; FVIIIa, activated factor VIII; FXa, activated factor X; HC II, heparin cofactor II; PC, phosphatidylcholine; PPACK, Pro-Phe-Arg-chloromethylketone; PS, phosphatidylserine. 
stored in aliquots at $-70^{\circ} \mathrm{C}$. An enzyme-linked immunosorbent assay was used to quantify FV, Gln506-FV, FVa, and Gln506-FVa antigen levels (25). The activated partial thromboplastin time (APTT) reagent (Actin FS) and the prothrombin time reagent (Innovin) were from Baxter Diagnostic Inc. (Deerfield, IL). Chromogenic substrate (CBS 34.47) for thrombin was from American Bioproducts (Parsippany, NJ). Heparin-Sepharose column (HiTrap) used to compare heparin affinities of different proteins was from Pharmacia, Uppsala, Sweden.

Normal human plasma was from Precision Biologicals (Dartmouth, Canada). AT III, HC II, and protein S-depleted plasmas were from Affinity Biologicals Inc. (Hamilton, Canada). In the experiments involving different depleted plasmas, the control normal human plasma was from Affinity Biologicals Inc., and it was plasma from the same pool that was used for the preparation of the depleted plasmas. FV-deficient plasma was from George King Biomedical, Inc. (Overland Park, KS). AT III-depleted plasma did not contain any detectable AT III in an immunoblot analysis with a sensitivity of $0.2 \%$ of AT III.

Dilinoleoyl phosphatidylcholine (PC) and dilinoleoyl phosphatidylserine (PS) in chloroform solution were from Avanti Polar Lipids, Inc. (Alabaster, AL). The phospholipid vesicles were prepared by first drying a mixture of phospholipids ( $80 \% \mathrm{PC}$ and $20 \% \mathrm{PS}$, wt/wt) under a gentle nitrogen stream and by then resuspending them into

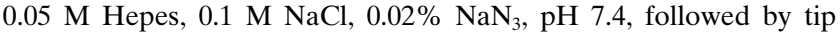
probe sonication for $20 \mathrm{~min}$ on ice. Finally, the vesicle suspension was passed through a polycarbonate membrane filter with $200-\mathrm{nm}$ pores (Poretics, Livermore, CA).

Clotting assays. Clotting assays were performed at $37^{\circ} \mathrm{C}$ with the Stago ST4 coagulometer (American Bioproducts Co., Parsippany, $\mathrm{NJ}$ ). APTT assays were done as follows. $50 \mu \mathrm{l}$ of plasma was mixed with $50 \mu \mathrm{l}$ of APTT reagent, $5 \mu \mathrm{l}$ of heparin, and with $5 \mu \mathrm{l}$ of APC in TBS ( $50 \mathrm{mM}$ Tris- $\mathrm{HCl}, 100 \mathrm{mM} \mathrm{NaCl}, 0.02 \% \mathrm{NaN}_{3}, \mathrm{pH} 7.4$ ), $0.5 \%$ BSA, $5 \mathrm{mM} \mathrm{CaCl}_{2}$. This mixture was incubated for $3 \mathrm{~min}$, after which the clotting was started by recalcification with $50 \mu$ l of TBS containing $20 \mathrm{mM} \mathrm{CaCl}_{2}$ and $0.5 \% \mathrm{BSA}$. The final concentrations of heparin and APC are shown in Results.

FXa-1 stage assays were performed as follows. $30 \mu \mathrm{l}$ of PC/PS vesicle suspension (final PC/PS concentration $51 \mu \mathrm{M}$ ) was mixed with $25 \mu \mathrm{l}$ of plasma, $4 \mu \mathrm{l}$ of a heparin sample, $5 \mu \mathrm{l}$ of an APC sample, and $10 \mu \mathrm{l}$ of FXa (final $0.52 \mathrm{nM}$ ) in TBS containing $0.5 \%$ BSA. The variable concentrations of heparin and APC are given in Results. After incubation for $3 \mathrm{~min}$, clotting was started by recalcification with $50 \mu \mathrm{l}$ of $20 \mathrm{mM} \mathrm{CaCl}$ in TBS.

FV inactivation assays were performed as follows. $300 \mu$ of PC/PS suspension $(8 \mu \mathrm{M}$ final) was mixed with $300 \mu \mathrm{l}$ of APC (40 pM final), $300 \mu \mathrm{l}$ of buffer or heparin $(0.1 \mathrm{U} / \mathrm{ml}$ final $)$, and $300 \mu \mathrm{l}$ of FV or FVa (100 pM final). 5- $\mu$ l aliquots were then withdrawn at various times and mixed with $50 \mu \mathrm{l}$ of FV-deficient plasma. Clotting was started by adding $50 \mu \mathrm{l}$ of prothrombin time reagent (Innovin). The observed clotting time was converted to residual FV or FVa activity by calibration curves obtained by adding variable amounts of purified $\mathrm{FV}$ or FVa to FV-deficient plasma.

To assess a potential heparin effect on FV activation by thrombin, FV $(300 \mathrm{nM})$ was incubated with heparin $(0.01$ or $0.1 \mathrm{U} / \mathrm{ml})$ or buffer at $37^{\circ} \mathrm{C}$ for $30 \mathrm{~min}$. Then $\alpha$-thrombin $(0.095 \mathrm{U} / \mathrm{ml}$ final $)$ was added and aliquots at $0-100 \mathrm{~min}$ were withdrawn and diluted in TBS, $0.5 \%$ BSA, $5 \mathrm{mM} \mathrm{CaCl}_{2} .5 \mu \mathrm{l}$ of diluted sample was mixed with $5 \mu \mathrm{l}$ of 500 $\mathrm{nM}$ of Pro-Phe-Arg-chloromethylketone (PPACK) to inhibit thrombin. This concentration of PPACK was separately shown not to influence the clotting time. Then the aliquots $(10 \mu \mathrm{l})$ were mixed with 50 $\mu l$ of FV-deficient plasma and the prothrombin time was used to determine FVa concentration. The calibration curve was obtained by first mixing varying amounts of purified FVa with PPACK and by then taking $10 \mu \mathrm{l}$ of this mixture and mixing it with $50 \mu \mathrm{l}$ of FV-deficient plasma.

Prothrombinase assays. Prothrombinase (PTase) assays were performed in TBS, $0.5 \%$ BSA, $5 \mathrm{mM} \mathrm{CaCl}_{2}$, pH 7.4. Phospholipid vesicles $(25 \mu \mathrm{M})$, variable concentrations of heparin and $17 \mathrm{pM}$ APC (or an equal volume of buffer for PTase activity in the absence of APC) were preincubated for $15 \mathrm{~min}$ at $37^{\circ} \mathrm{C}$. FV or FVa $(20 \mathrm{pM})$ was added and incubated $\left(37^{\circ} \mathrm{C}\right)$ for variable times (0 to $\left.20 \mathrm{~min}\right)$ to let APC inactivate FV or FVa. After adding $1 \mathrm{nM} F X a$ and $1 \mu \mathrm{M}$ prothrombin, aliquots were taken at $1,2,3$, and $4 \min \left(37^{\circ} \mathrm{C}\right)$ and quenched with $10 \mathrm{mM}$ EDTA in TBS, $0.5 \%$ BSA, $\mathrm{pH}$ 8.5. Thrombin formation was assessed with $0.6 \mathrm{mM}$ CBS 34.47 chromogenic substrate using a microplate reader (EL 312 E Microplate; Bio-Tek Instruments, Winooski, VT) using Kineticalc software. In some experiments where indicated, $87 \mathrm{nM}$ protein $\mathrm{S}$ was present with other reactants in the preincubation mixture.

SDS-PAGE analysis of FV cleavage by APC. FV (110 nM), APC $(4.2 \mathrm{nM})$, and PC/PS $(52 \mu \mathrm{M})$ in $120 \mu \mathrm{l}$ were incubated at $37^{\circ} \mathrm{C}$ with or without $1.0 \mathrm{U} / \mathrm{ml}$ of heparin. At various times, aliquots of $20 \mu \mathrm{l}$ were drawn, the reaction was quenched by $20 \mu \mathrm{l}$ of $125 \mathrm{mM}$ Tris$\mathrm{HCl}, 10 \mathrm{mM}$ EDTA, 2.5\% SDS, 25\% glycerol, pH 6.8 and SDSPAGE was performed using $5 \%$ or $10 \%$ gels. The proteins on a gel were visualized by immunoblotting or stained with ISS Pro-blue staining system (Enprotech, Hyde Park, MA) according to instructions by the manufacturer. For immunoblotting, proteins from polyacrylamide gels were transferred to nitrocellulose membranes (Biorad, Hercules, CA), which were then blocked with $1 \%$ casein in TBS. A monoclonal anti-heavy chain FVa antibody in TBS, $1 \%$ casein was incubated with the membrane for $2 \mathrm{~h}$ at room temperature. After washing the membrane with TBS, biotinylated anti-mouse IgG $(1 \mu \mathrm{g} /$ $\mathrm{ml})$, streptavidin alkaline phosphatase $(1 \mu \mathrm{g} / \mathrm{ml})$, and BCIP/NBT substrate were used for development.

All experiments were done at least on two occasions with good agreement in results. Unless otherwise mentioned, representative experiments are presented in the figures.

\section{Results}

Clotting experiments. The ability of APC to alter the property of heparin to prolong the APTT of normal plasma was determined (Fig. 1, top). In the absence of APC, heparin at $0.03 \mathrm{U} / \mathrm{ml}$ prolonged the APTT from 51 to $73 \mathrm{~s}$. When APC was present at $1.5,5$, or $10 \mathrm{nM}$, plasma became unclottable (APTT $>1,000 \mathrm{~s}$ ) at heparin levels of $<0.016,<0.008$, and $<0.002 \mathrm{U} / \mathrm{ml}$, respectively. Since identical results were obtained with three different commercial heparin preparations tested (data not shown) we used only one heparin preparation (Sigma Chemical Co.) for further experiments. The ability of APC to influence heparin's anticoagulant activity in FXa-1 stage assays was also determined (Fig. 1, bottom). These assays are independent of factor VIIIa (FVIIIa). The results were essentially similar to those for APTT assays with the exception that the FXa-1 stage assay in the absence of APC was more sensitive to heparin. For example, in the absence of exogenous APC, $0.03 \mathrm{U} / \mathrm{ml}$ heparin increased the FXa-1 stage clotting time from 45 to $560 \mathrm{~s}$ while in APTT assays the same heparin concentration only prolonged the clotting time from 51 to $73 \mathrm{~s}$. In both APTT and FXa-1 stage assays, $0.008 \mathrm{U} / \mathrm{ml}$ of heparin in combination with $5 \mathrm{nM}$ APC rendered plasma unclottable within the 1000 -s observation time.

Studies of APC-heparin synergy using FXa-1 stage assays were made to allow comparison between control plasma and plasmas depleted of AT III, HC II, or protein S (Fig. 2). Apparently due to the lack of all AT III-dependent heparin functions, AT III-depleted plasma was markedly heparin resistant. For example, in the absence of APC, the FXa-1 stage clotting time of AT III-depleted plasma was $38 \mathrm{~s}$ in the absence of heparin and $38 \mathrm{~s}$ in the presence of $1.0 \mathrm{U} / \mathrm{ml}$ of heparin. In con- 

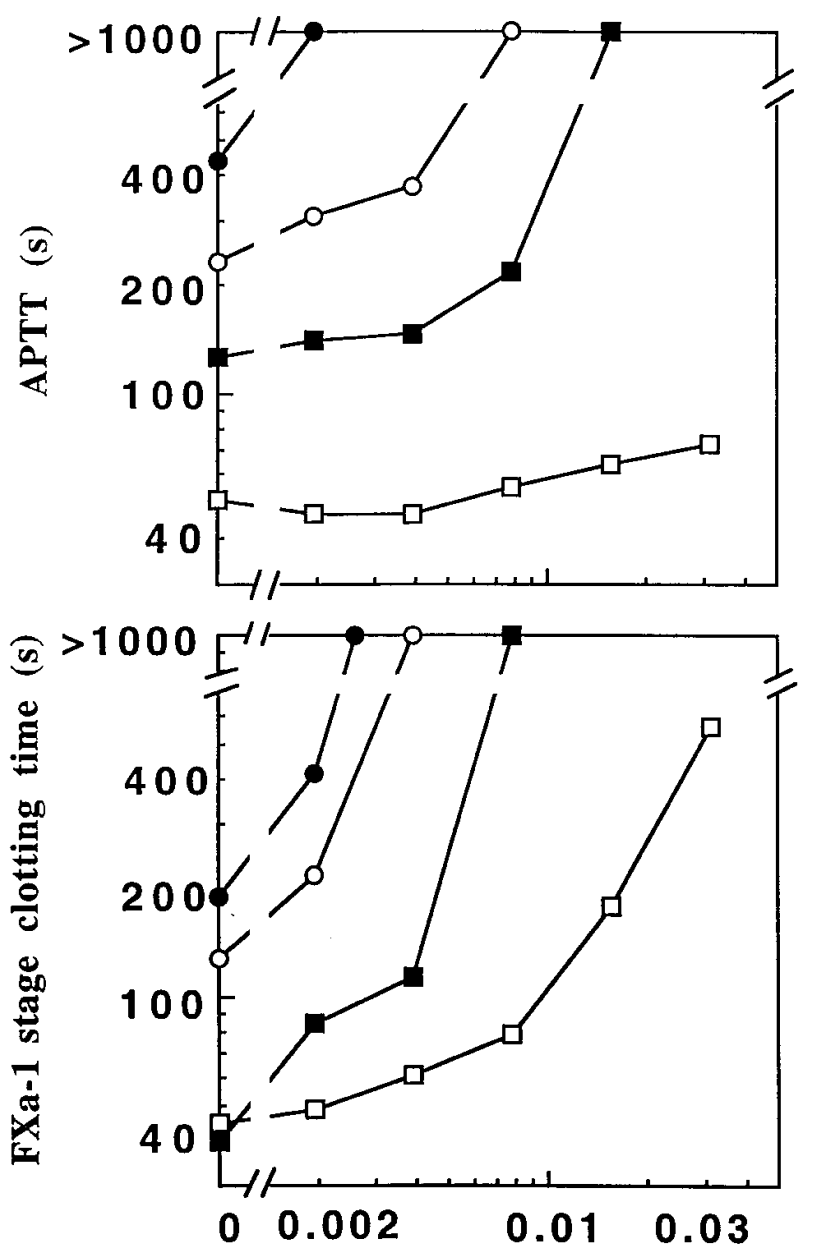

Heparin $(\mathrm{U} / \mathrm{ml})$

Figure 1. APTT and FXa-1 stage clotting times in the absence and presence of varying concentrations of APC and heparin. Normal human plasma, APC, and heparin plus either an APTT reagent (top) or FXa and phospholipid (PC/PS) vesicles (bottom) were incubated for $3 \mathrm{~min}$ at $37^{\circ} \mathrm{C}$ before recalcification as described in Methods. Open squares, no APC; closed squares, APC $1.5 \mathrm{nM}$ (top) or $5 \mathrm{nM}$ (bottom); open circles, APC $5 \mathrm{nM}$ (top) or $10 \mathrm{nM}$ (bottom); solid circles, APC 10 $\mathrm{nM}($ top $)$ or $20 \mathrm{nM}$ (bottom).

trast, the control plasma, without added APC, became unclottable at $\geq 0.03 \mathrm{U} / \mathrm{ml}$ heparin. Thus, it was impossible to quantitatively compare the heparin dependence of APC induced clotting time prolongations in AT III-depleted plasma with those observed for normal plasma. However, the FXa-1 stage clotting time ratio defined as the ratio of the FXa-1 stage clotting time in the presence of $10 \mathrm{nM}$ APC divided by the clotting time in the absence of APC in AT III-depleted plasma increased from 3.8 to $\geq 28.0$ when heparin was increased from 0 to $0.5 \mathrm{U} / \mathrm{ml}$ indicating the presence of a remarkable effect of heparin on the observed anticoagulant activity of APC even in AT III-depleted plasma (Fig. 2). Upon reconstitution of AT III-depleted plasma with purified AT III, heparin sensitivity of this plasma both in the presence and absence of APC was restored indicating that the heparin resistance of the AT IIIdepleted plasma preparation was specifically due to AT III de-

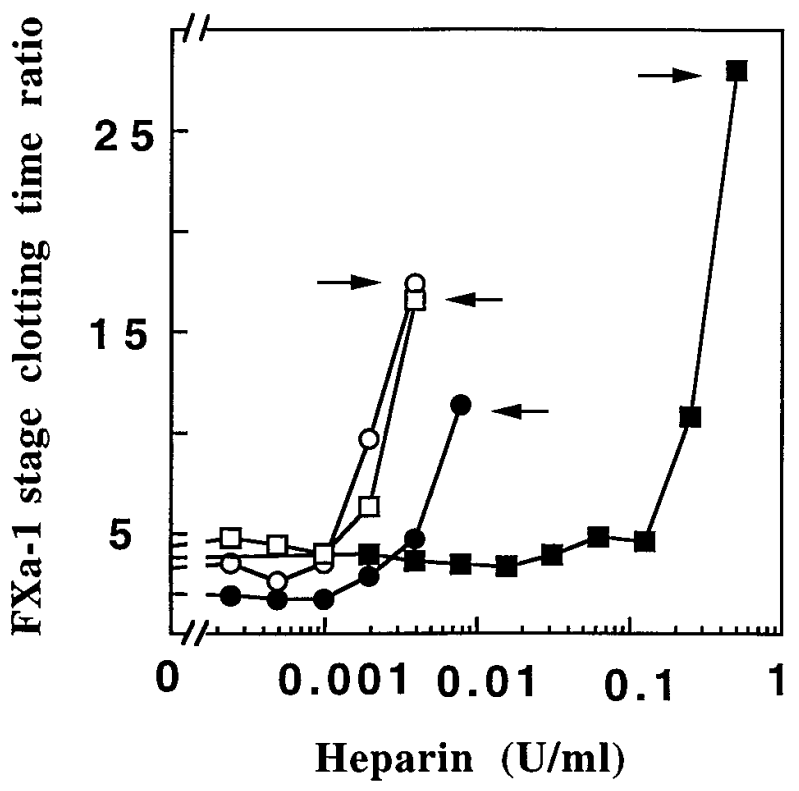

Figure 2. Effect of heparin on APC-dependent prolongation of FXa-1 stage clotting time in normal plasma, and in plasma depleted of AT III, protein S, or HC II in the absence and in the presence of varying doses of heparin. The FXa-1 stage clotting time ratio was defined as the ratio of the clotting time in the presence of $10 \mathrm{nM} \mathrm{APC}$ divided by clotting time in the absence of APC. APC, PC/PS vesicles, and heparin were incubated with plasma for $3 \mathrm{~min}$ at $37^{\circ} \mathrm{C}$ before recalcification. For points indicated by arrows, the lower limit of the ratio was calculated by dividing $1,000 \mathrm{~s}$, the upper limit of clotting time observation, by the corresponding clotting time in the absence of APC. Open squares, normal plasma; solid squares, AT III-depleted plasma; open circles, HC II-depleted plasma; solid circles, protein $\mathrm{S}$-depleted plasma.

pletion (data not shown). Studies of the FXa-1 stage clotting time ratio using $\mathrm{HC}$ II-depleted plasma (Fig. 2) showed that there was no influence of HC II on the phenomena observed in Fig. 1. For protein S-depleted plasma, the FXa-1 stage clotting time ratio was $29-51 \%$ of the corresponding ratio in control plasma from no heparin up to $0.004 \mathrm{U} / \mathrm{ml}$ heparin, respectively. Heparin at $0.008 \mathrm{U} / \mathrm{ml}$ was needed to render protein S-depleted plasma unclottable while $0.004 \mathrm{U} / \mathrm{ml}$ heparin was enough for the same effect for the control plasma (Fig. 2). Upon reconstitution of protein S-depleted plasma with purified protein $\mathrm{S}$, the FXa-1 stage clotting times in the presence of APC were prolonged whether or not heparin was present. In the presence of $10 \mathrm{nM}$ APC, addition of $140 \mathrm{nM}$ of protein $\mathrm{S}$ to protein S-depleted plasma increased the clotting time from 74 to $96 \mathrm{~s} \mathrm{(30 \%} \mathrm{increase)} \mathrm{in} \mathrm{the} \mathrm{absence} \mathrm{of} \mathrm{heparin} \mathrm{and} \mathrm{from} 88$ to $112 \mathrm{~s}(27 \%$ increase) in the presence of $0.001 \mathrm{U} / \mathrm{ml}$ of heparin. Thus, the effect of protein S depletion on APC response, both in the presence and absence of heparin, could be attributed to the loss of protein S APC cofactor activity and no specific protein S-heparin interaction could be inferred from the clotting data.

The time course of FV and FVa inactivation by APC was measured in the absence and presence of $0.1 \mathrm{U} / \mathrm{ml}$ heparin. As shown in Fig. 3, the rate of FVa inactivation by APC was similar whether heparin was present or absent. However, for FV inactivation by APC a significant influence of $0.1 \mathrm{U} / \mathrm{ml}$ heparin 


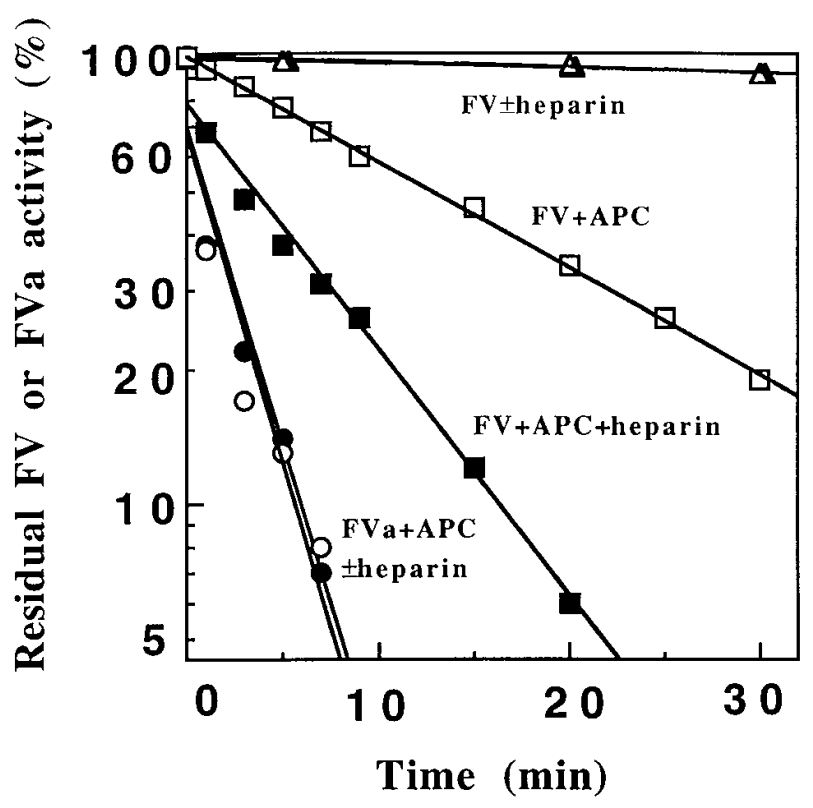

Figure 3. Time course of inactivation of FV or FVa by APC in the absence and presence of $0.1 \mathrm{U} / \mathrm{ml}$ heparin. APC $(40 \mathrm{pM})$, PC/PS vesicles $(2.5 \mu \mathrm{M})$, and $\mathrm{FV}$ or FVa $(100 \mathrm{pM})$ were incubated $\left(37^{\circ} \mathrm{C}\right)$ with or without $0.1 \mathrm{U} / \mathrm{ml}$ heparin. At various times as indicated, aliquots were removed, added to FV-deficient plasma, and the prothrombin time was measured. Clotting times were converted to residual FV or FVa activity using appropriate standard curves. Open squares, FV without heparin; solid squares, FV with heparin; open circles, FVa without heparin; solid circles, FVa with heparin; open triangles, FV without heparin and APC; solid triangles, FV with heparin but without APC.

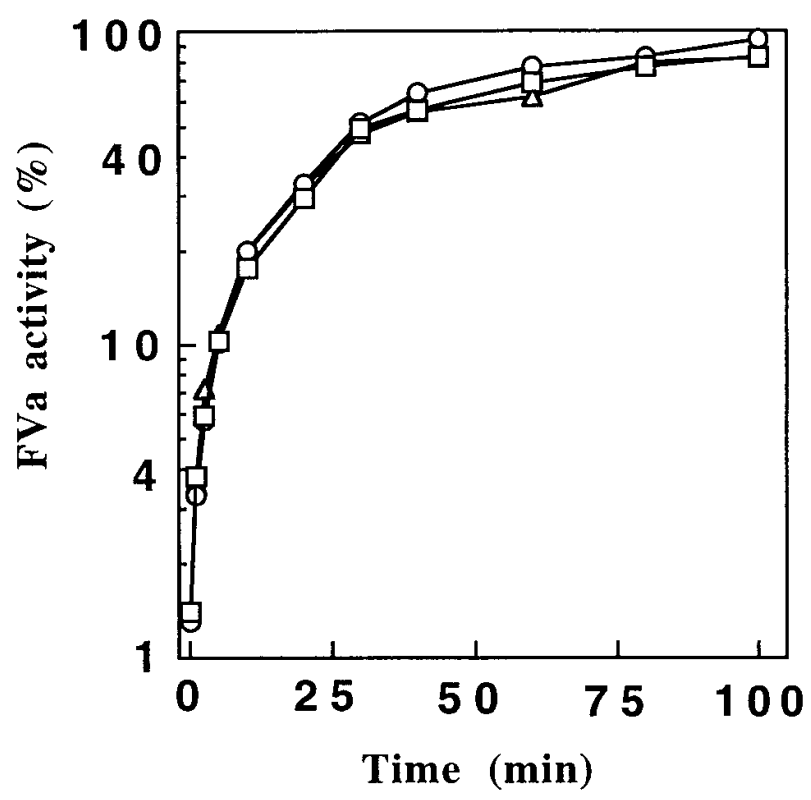

Figure 4. Activation of FV by thrombin in the absence and presence of 0.01 or $0.1 \mathrm{U} / \mathrm{ml}$ heparin. FV $(300 \mathrm{nM})$ and $\alpha$-thrombin $(0.095$ $\mathrm{U} / \mathrm{ml})$ were incubated $\left(37^{\circ} \mathrm{C}\right)$ with buffer or with 0.01 or $0.1 \mathrm{U} / \mathrm{ml}$ heparin. At indicated times, aliquots were withdrawn and diluted in buffer, after which thrombin was inactivated with $500 \mathrm{nM}$ of PPACK. This concentration of PPACK was separately shown not to influence the clotting time. Then FVa activity was determined using prothrombin time assay in FV-deficient plasma. The clotting times were converted to FVa activity using a standard curve obtained with purified $\mathrm{FVa}$. The results were expressed as percentage of original FV concentration; $100 \%$ indicating complete activation of FV. Open squares, no heparin; open circles, heparin $0.01 \mathrm{U} / \mathrm{ml}$; open triangles, heparin 0.1 $\mathrm{U} / \mathrm{ml}$.

tivity, inactivation of FV by APC was linear up to 10 min and a heparin dose-dependent enhancement of APC action was observed (Fig. 5). Under these conditions, 0.1, 0.6, and $1.0 \mathrm{U} / \mathrm{ml}$ heparin, compared with no heparin, increased the rate of FV inactivation by APC by 1.9-, 2.9-, and 3.6-fold, respectively. To exclude a possible effect from trace amounts of thrombin in APC preparations, a control experiment was performed where APC was treated with hirudin before FV inactivation. In two duplicate experiments with the hirudin-treated APC, mean residual FV activities in the presence and absence of $1.0 \mathrm{U} / \mathrm{ml}$ heparin were 43 and $83 \%$, respectively. Thus, the hirudin pretreatment of APC did not affect the heparin enhancement of FV inactivation by APC. The time course of FV inactivation by APC was also studied in the presence of protein $\mathrm{S}(87 \mathrm{nM})$. The rate of inactivation of FV by APC was increased by $1.0 \mathrm{U} / \mathrm{ml}$ heparin similarly in the absence or presence of protein $\mathrm{S}$ (data not shown), suggesting no influence of heparin on protein $S$ cofactor activity.

To study whether APC that was carried over to the PTase assay directly contributed to PTase inhibition, experiments were performed with no separate preincubation of APC and FV. Preincubation of APC and PC/PS vesicles \pm heparin was followed by simultaneous addition of $\mathrm{FXa}, \mathrm{FV}$, and prothrombin to initiate PTase activity. In these conditions, no measurable FV/FVa inhibition by APC was seen in accordance with observations that FV is very rapidly converted to FVa under 


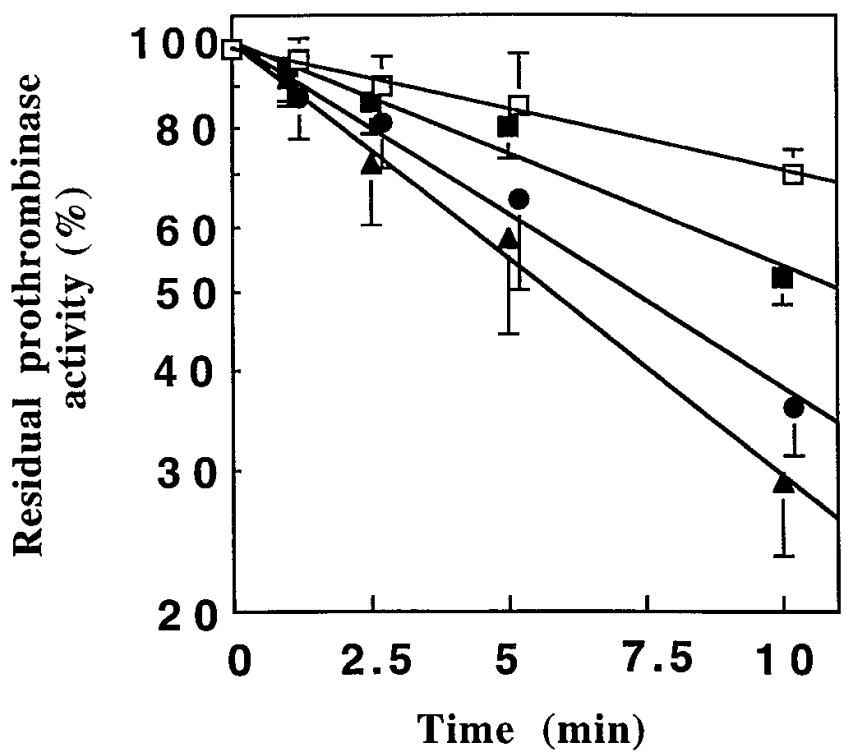

Figure 5. Time course of FV inactivation by $\mathrm{APC}$ at various heparin concentrations. PC/PS vesicles $(25 \mu \mathrm{M})$, APC (17 pM), and heparin as indicated were incubated $\left(37^{\circ} \mathrm{C}\right)$ with each other for $15 \mathrm{~min}$. Then $\mathrm{FV}(20 \mathrm{pM})$ was added and incubated $\left(37^{\circ} \mathrm{C}\right)$ for the times indicated. FXa $(1 \mathrm{nM})$ and prothrombin $(1 \mu \mathrm{M})$ were then added and prothrombinase activity was measured as described in Methods. Each point of residual activity was calculated by subtracting data for controls with no APC. Data shown are mean and SD of four experiments. Symbols: open squares, no heparin; solid squares, heparin 0.1 $\mathrm{U} / \mathrm{ml}$; solid circles, heparin $0.6 \mathrm{U} / \mathrm{ml}$; solid triangles, heparin $1.0 \mathrm{U} / \mathrm{ml}$.

these conditions and that $\mathrm{FXa}$ protects $\mathrm{FVa}$ from inactivation by $\operatorname{APC}(26,27)$.

Control experiments ruled out any effects of heparin on the PTase assay that was used to quantitate FV and FVa. First, PTase assays were performed without FV or FVa. Under conditions in which thrombin formation was linear over time, there was no inhibitory effect of heparin on PTase activity whether APC was present or absent (data not shown). Thus, the presence of FV was required for observing the heparin an-

Table I. Effect of Different FVs and FVas on Inhibition of Prothrombinase by APC in the Absence and Presence of Heparin

\begin{tabular}{llc}
\hline & \multicolumn{2}{c}{ Residual prothrombinase activity } \\
\cline { 2 - 3 } & No heparin & $1.0 \mathrm{U} / \mathrm{ml}$ heparin \\
\hline Normal FVa & $32 \pm 5.3 \%$ & $29 \pm 4.3 \%$ \\
Gln506-FVa & $82 \pm 6.8 \%$ & $68 \pm 11 \%$ \\
Normal FV & $64 \pm 6.6 \%$ & $25 \pm 6.0 \%$ \\
Gln506-FV & $90 \pm 5.7 \%$ & $36 \pm 9.9 \%$
\end{tabular}

PC/PS vesicles $(25 \mu \mathrm{M}), \mathrm{APC}(17 \mathrm{pM})$, and heparin $(1.0 \mathrm{U} / \mathrm{ml})$ or buffer were incubated $\left(37^{\circ} \mathrm{C}\right)$ with each other for $15 \mathrm{~min}$. Then, FV, Gln506$\mathrm{FV}$, FVa, or Gln506-FVa $(20 \mathrm{pM})$ was added and incubated $\left(37^{\circ} \mathrm{C}\right)$ for $20 \mathrm{~min}$. FXa $(1 \mathrm{nM})$ and prothrombin $(1 \mu \mathrm{M})$ were added and prothrombinase activity measured as described in Methods. The residual prothrombinase activity was calculated against control with no APC but with the corresponding FV or FVa. The data shown are mean \pm SD from six experiments. ticoagulant effect in this system of purified proteins. At $37^{\circ} \mathrm{C}$, $25 \mu \mathrm{M}$ PC/PS vesicles, $1 \mathrm{nM}$ FXa and 20 or $40 \mathrm{pM} \mathrm{FV}$ were preincubated for $15 \mathrm{~min}$ with or without $1.0 \mathrm{U} / \mathrm{ml}$ heparin after which prothrombin $(1 \mu \mathrm{M})$ was added and PTase activity was measured. The PTase activity, in the presence of $1.0 \mathrm{U} / \mathrm{ml}$ heparin, was $99 \pm 6.6 \%$ (mean $\pm \mathrm{SD}, n=4)$ of the PTase activity in the absence of heparin. PTase activity observed for $20 \mathrm{pM}$ of $\mathrm{FV}$ was $53 \%$ of that for $40 \mathrm{pM} \mathrm{FV}$, verifying that the assay was linear with respect to $\mathrm{FV}$ concentration.

Availability of purified Gln506-FV and Gln506-FVa offered a possibility to test whether cleavage at Arg 506 of normal FV (not occurring in Gln506-FV) would be essential for the observed heparin effect. As shown in Table I, heparin clearly enhanced inactivation of both normal FV and Gln506FV by APC. This experiment confirmed the finding in plasma based FV/FVa inactivation assay of almost no heparin effect on FVa inactivation but a clear effect on FV inactivation.

$S D S-P A G E$ analysis. The effects of heparin on the limited proteolysis of FV by APC are shown in Fig. 6, $A$ and $B$. In Fig. $6 A$, three differences between the presence and absence of heparin were observed. First, there was enhanced rate of appearance of material with molecular mass between 200,000 and $330,000 \mathrm{D}$ in the presence of heparin compared with its absence. Second, heparin clearly enhanced the rate of appearance of a single band at 45,000 D. Third, a fainter band at $30,000 \mathrm{D}$ was present and its rate of appearance was enhanced by heparin. To study whether the material between 200,000 and $330,000 \mathrm{D}$ would present a single cleavage product, the experiment was repeated using a gel containing 5\% of acrylamide to allow better separation between bands in the high
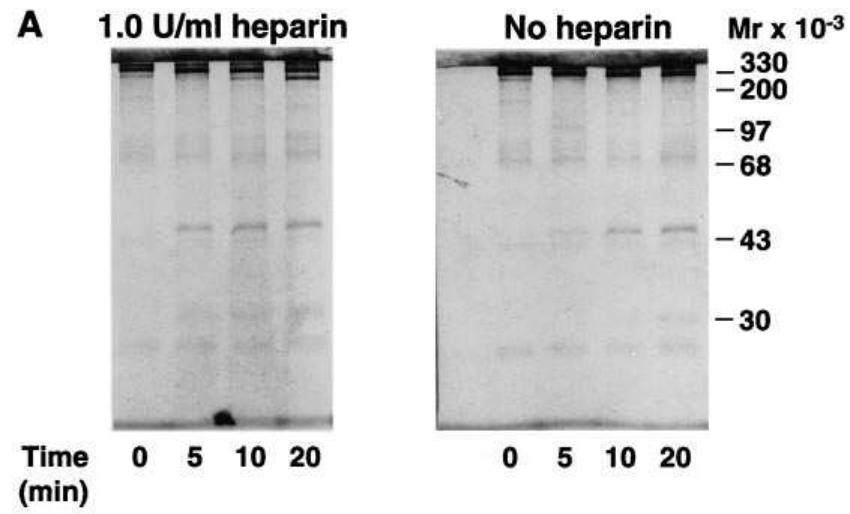

B
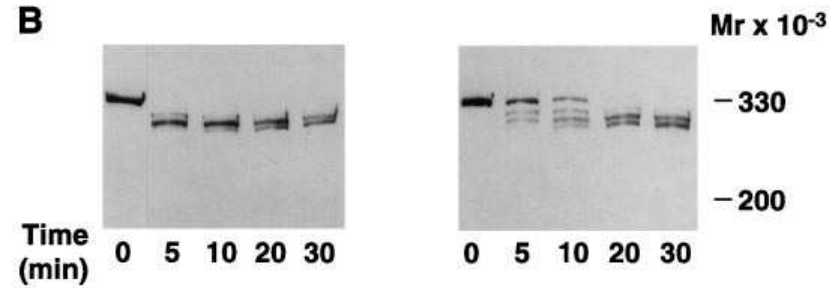

Figure 6. Limited proteolysis of FV by APC in the absence and presence of $1.0 \mathrm{U} / \mathrm{ml}$ heparin. FV (110 nM), APC (4.2 nM), and PC/PS vesicles $(52 \mu \mathrm{M})$ were incubated at $37^{\circ} \mathrm{C}$ for times indicated after which aliquots were withdrawn, quenched, and subjected to SDSPAGE as described in Methods. $(A)$ A $10 \%$ SDS-PAGE using Problue staining. $(B)$ An immunoblot using a 5\% SDS-PAGE and a monoclonal anti-FV heavy chain antibody. 
molecular weight region. As shown in Fig. $6 B$, there were actually three separate bands below single-chain FV but above 200,000 D. In the presence of heparin, the two uppermost bands of this triplet showed peak intensity already at $5 \mathrm{~min}$ with subsequent decrease in intensity between 10 and $30 \mathrm{~min}$. In the absence of heparin, the rate of their appearance as well as the rate of disappearance of single-chain FV was slower (Fig. $6 \mathrm{~B}$ ). Thus, the rate of limited proteolysis of FV by APC was clearly enhanced by heparin and the process seemed to involve more than one cleavage site. When FVa $(73 \mathrm{nM})$ was incubated with APC $(0.17 \mathrm{nM})$ and PC/PS $(52 \mu \mathrm{M})$ with or without $1.0 \mathrm{U} / \mathrm{ml}$ heparin for up to $20 \mathrm{~min}$, no influence of heparin on the time course of FVa proteolysis was seen (data not shown). FV (200 nM) and $1.0 \mathrm{U} / \mathrm{ml}$ heparin were also incubated with $4.2 \mathrm{nM}$ of APC and PC/PS $(52 \mu \mathrm{M})$ in the presence and absence of $1.0 \mathrm{U} / \mathrm{ml}$ AT III. AT III did not alter the time course of limited proteolysis of FV by APC.

Additional experiments. To study the relative heparin affinities of protein C, APC, AT III, FV, and FVa, these purified proteins were applied at room temperature to a $1.0-\mathrm{ml}$ heparin-Sepharose column in a buffer of $20 \mathrm{mM}$ Tris- $\mathrm{HCl}, 50 \mathrm{mM}$ $\mathrm{NaCl}$, and $5 \mathrm{mM} \mathrm{CaCl}_{2}, \mathrm{pH}$ 7.4. Elution $(2.0 \mathrm{ml}$ fractions, total volume $60 \mathrm{ml}$ ) was performed at $0.5 \mathrm{ml} / \mathrm{min}$ flow rate with a linear $50-1,050 \mathrm{mM} \mathrm{NaCl}$ gradient. The proteins were eluted from the column in the following order: protein $\mathrm{C}$ at $130-160$ $\mathrm{mM} \mathrm{NaCl}, \mathrm{FV}$ and FVa at $210-320 \mathrm{mM} \mathrm{NaCl}$, APC at 290-360 $\mathrm{mM} \mathrm{NaCl}$, and AT III at $750-890 \mathrm{mM} \mathrm{NaCl}$. Thus, under physiological ionic strength and $\mathrm{Ca}^{2+}$ concentration, APC, but not protein $\mathrm{C}$, as well as FV and FVa showed significant heparin affinity.

Since DNA, like heparin, is a negatively charged polymer and since it may be released into blood, it was of interest to assess possible effects of purified DNA on APC function. Addition of DNA up to $23 \mu \mathrm{g} / \mathrm{ml}$ did not affect PTase activity in absence of APC and did not affect the ability of APC to inactivate $\mathrm{FV}$ in the presence of PC/PS vesicles when PTase assays were used to measure residual FV.

\section{Discussion}

Remarkable anticoagulant effects of the simultaneous presence of APC and heparin are demonstrated here based on APTT and FXa-1 stage clotting assays. These findings are consistent with one other report (22). The therapeutic range of heparin concentrations is 0.2 to $0.8 \mathrm{U} / \mathrm{ml}(28)$ and the basal physiological concentration of APC is 40 to $80 \mathrm{pM}(29,30)$ which can rise by 10 - to 100 -fold upon stimulation of protein $\mathrm{C}$ activation or during therapeutic use of $\operatorname{APC}(29,31)$. Further, when PTase assays were used to measure APC activity in the absence of AT III with heparin concentrations covering the therapeutic range ( 0.1 to $1.0 \mathrm{U} / \mathrm{ml})$, an effect of heparin on APC action was seen with APC as low as $17 \mathrm{pM}$. Thus, concentrations of APC and heparin used in this study were potentially physiological and pharmacologically relevant.

Several conclusions from the clotting experiments using plasmas depleted of specific proteins could be drawn. First, the APC effect on heparin sensitivity of plasma seemed independent of HC II. Second, the FXa-1 stage clotting time ratio increased by 7.4 -fold in AT III-depleted plasma suggesting that observable APC-heparin synergism did not necessarily require AT III. Third, the absence or presence of protein S affected the APC induced prolongation of clotting time similarly whether heparin was present or absent. Thus, heparin did not enhance the APC cofactor effect of protein S $(32,33)$. Fourth, experiments using FXa-1 stage assays showed that the heparin-APC synergism did not require FVIII or FVIIIa. This latter point is an important consideration for mechanistic interpretations since APC may exert its physiological action partly through inactivation of FVIII or FVIIIa (34-37) and since heparin directly inhibits activation of FVIII by thrombin in an AT III-independent manner $(1,4,5,38)$.

Heparin markedly inhibits FV activation in plasma by thrombin when AT III is present (39-44); furthermore, provided that very high concentrations of heparin $(\geq 2.0 \mathrm{U} / \mathrm{ml})$ are present, heparin is inhibitory in the absence of AT III (1). Under the conditions of the present study using purified proteins, any significant heparin effect on FV activation by thrombin was excluded. First, activation of purified FV by thrombin was not affected by heparin up to $0.1 \mathrm{U} / \mathrm{ml}$. Second, PTase activity, with FV being the rate limiting reagent, was unaffected by heparin up to $1.0 \mathrm{U} / \mathrm{ml}$ heparin as previously reported (4), although we did observe inhibition of PTase by 2.0 to $120 \mathrm{U} / \mathrm{ml}$ heparin in the absence of AT III. In addition to thrombin, FXa can also activate FV (45-47). Under our experimental conditions using purified proteins, heparin effects on interactions between FXa and FV were not observed.

Enhancement of APC anticoagulant activity by heparin in normal plasma was at least in part AT III independent since PTase experiments that showed heparin effects in the presence of APC were seen in the absence of AT III and since the presence of AT III did not enhance the heparin effect on proteolytic inactivation of FV by APC in reaction mixtures containing only purified proteins. While the enhancement by heparin of FV inactivation by APC was AT III independent in purified systems, the final anticoagulant synergism of APC and heparin in plasma was certainly influenced by AT III-dependent anticoagulant mechanisms of heparin. In AT III-depleted plasma, AT III-dependent inhibition of FXa, of thrombin and of the feedback activation of FV by thrombin are not possible. Accordingly, more heparin was needed for APC-heparin synergism in AT III-depleted plasma than in normal plasma, yet in AT III-depleted plasma, heparin increased the APC induced prolongation of clotting time by 7.4 -fold (Fig. 2). This effect may reflect the novel mechanism shown here using purified proteins, namely the potentiation by heparin of FV inactivation by APC. Remarkably, this enhancement of APC action by heparin was not observed when the substrate was FVa instead of FV.

APC inactivates membrane-bound FV more slowly than membrane-bound FVa $(26,35,48-52)$. However, both the pattern and the order of cleavages is different for proteolytic inactivation of $\mathrm{FVa}$ and FV. It was reported that inactivation of FVa by APC involves an initial cleavage at Arg 506 followed by cleavage at Arg 306, with some possible contribution from subsequent cleavage at Arg 679 in the heavy chain, whereas FV is principally cleaved at Arg 306 (49). FV can also be cleaved at Arg 506, Arg 679, and Lys 994 after cleavage at Arg 306 (49). For inactivation of Gln506-FVa, APC cleaves at Arg $306(25,53)$. In the current SDS-PAGE analysis, enhanced appearances of $\sim 285,000$ and 45,000 D fragments were consistent with the principal role of Arg 306 cleavage (49) and showed that this cleavage was enhanced by heparin. However, the data on high molecular weight fragments of FV (Fig. $6 \mathrm{~B}$ ) and on the 30,000-D band (Fig. $6 A$ ) suggested that the heparin 
enhancement of FV proteolysis by APC may involve more than one cleavage site. Actually, the enhanced rate of appearance of the 30,000-D band suggested involvement of the cleavage at Arg 506 of FV, since Kalafatis et al. (49), also observing the 30,000 -D band, showed it to be the fragment from the residue 307 to the residue 506 .

The molecular mechanism(s) by which heparin enhanced proteolysis of FV by APC remains to be defined. Under the physiological ionic strength, both APC and FV readily attach to heparin (elution of both proteins from heparin-Sepharose required supraphysiological ionic strength). Therefore, one explanation could involve heparin as a template on which APC and FV would bind in favorable orientation to each other. The reason for the lack of heparin enhancement of inactivation of FVa by APC is not clear. In addition to possible conformational differences between FV and FVa involving the A1, A2, A3, C1, and C2 domains, it should be noted that thrombinactivated FVa lacks the large connecting region, residues 710$1545(45,54)$. Thus, the presence of the connecting region of FV might directly or indirectly facilitate the heparin effect on APC action.

Although FVa, rather than FV, has usually been discussed as the physiological substrate of APC, we submit that heparin enhancement of FV inactivation by APC could be important in vivo. Upon vascular trauma, initially only small amounts of thrombin are formed through activation of the coagulation cascade. Subsequently, thrombin can greatly enhance its own formation through feedback activation of FVIII and FV (42). Accordingly, a major anticoagulant function of heparin is its ability to suppress the activation of FVIII and FV through AT III-dependent inhibition of thrombin (39-43, 47, 55, 56). For example, when thrombin formation in defibrinated FXadepleted plasma was assessed by following prothrombin fragment $\mathrm{F} 1+2$ formation after triggering coagulation by si- multaneous addition of FXa and calcium, heparin had no inhibitory effect on thrombin formation if $\mathrm{FV}$ was activated by preincubation with thrombin before adding heparin (40). In contrast, when FVa had to be generated in situ, thrombin generation was effectively inhibited by heparin (40). Thus, heparin significantly inhibited prothrombin activation primarily by inhibiting FVa generation (40). Often the limiting factor for PTase assembly in vivo is phospholipid and/or receptor availability for binding FV or FVa. Both FV and FVa have a high affinity for phospholipids (57). Thus, heparin-mediated APC action that decreases the amount of membrane-bound FV capable of conversion to FVa and that blocks FV/FVa binding sites by inactivated FV could be important for downregulation of thrombin generation and coagulation.

We propose that anticoagulant synergism between APC and AT III in the regulation of PTase could occur as schematically presented in Fig. 7. Upon exposure of procoagulant phospholipid membrane binding sites, FV attaches to the surface sites where it can be converted to FVa by FXa and/or thrombin (45). Membrane-bound FVa can be inactivated by APC and protein $\mathrm{S}$, which is not shown in Fig. 7 for simplification, without enhancement by heparin. Because of FXa protection of FVa from $\operatorname{APC}(26,27)$, the rate of the inactivation of FVa in PTase complexes is less than that of FVa not complexed with FXa. With therapeutic heparin concentrations, FV feedback activation to FVa by thrombin is significantly inhibited by AT III, whereas at subtherapeutic heparin concentrations, FV feedback activation by thrombin is less inhibited by AT III. At subtherapeutic heparin levels, heparin-stimulated cleavage of membrane-bound FV by APC may become a significant regulator of FV availability for conversion to FVa and PTase assembly. For example, addition of $0.016 \mathrm{U} / \mathrm{ml}$ of heparin to plasma containing APC rendered the plasma unclottable. In parallel to our emphasis on the significance of heparin-enhanced

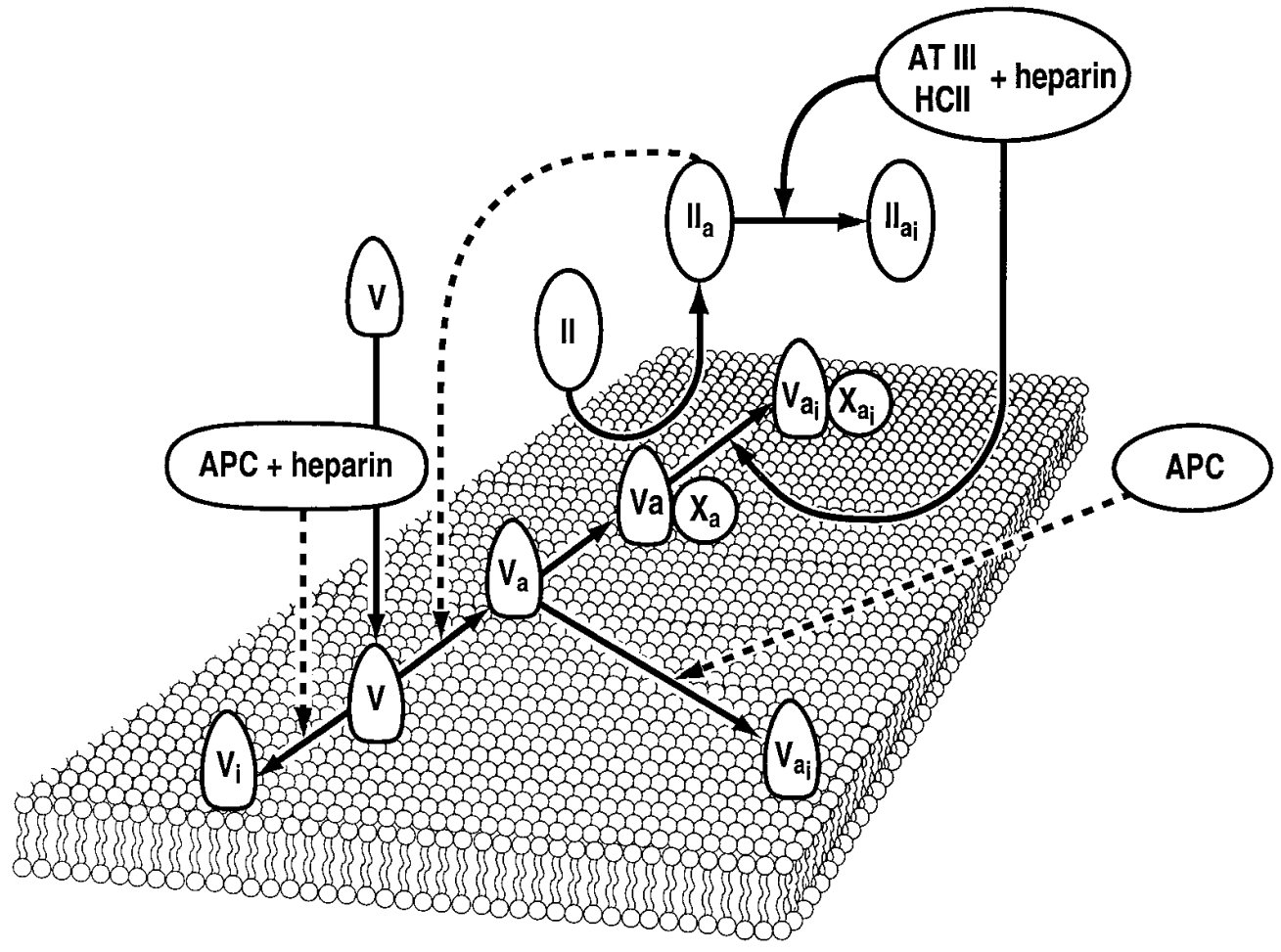

Figure 7. A proposed scheme for regulation of availability of membrane-bound factor Va for prothrombinase assembly by antithrombin III, APC, and heparin. For explanation, see Discussion. AT III, antithrombin III; HC II, heparin cofactor II; $\mathrm{V}$, factor V; Va, activated factor $\mathrm{V} ; \mathrm{V}_{\mathrm{i}}$, inactivated $\mathrm{V} ; \mathrm{Va}_{\mathrm{i}}$, inactivated $\mathrm{Va}$; Xa, activated factor $\mathrm{X}$; II, prothrombin; IIa, thrombin. 
FV inactivation by APC, Kalafatis et al. (52) recently suggested that at elevated APC concentrations, inactivation of membrane-bound FV by APC may become faster than activation of FV by thrombin or FXa and that FV inactivation may become a major determinant of clot formation.

What could be some practical consequences of this novel heparin function, i.e., enhancement of APC action on FV? First, purified APC may prove to be more useful as an antithrombotic drug (16-18) than traditional anticoagulants in selected situations. For example, APC may be superior to heparin in preventing reocclusion of coronary arteries after thrombolysis (58). Combining low-dose heparin with APC or with APC and thrombolytic agents might render the pharmacologic use of APC, which is expensive, more feasible. Second, the high affinity of APC for heparin (59) suggests that flushing heparin-coated artificial surfaces with APC might help to decrease problems like catheter-triggered thrombosis (60) or the coagulopathy triggered by artificial surface during cardiopulmonary bypass $(61,62)$. Third, small amounts of thrombin preferentially activate protein $\mathrm{C}$ instead of acting as procoagulant in vivo increasing circulating APC levels up to 100-fold $(24,29,31)$. Increased APC production could potentiate both heparin-induced anticoagulation as well as bleeding in clinical situations with increased thrombin formation, e.g., during cardiopulmonary bypass or disseminated intravascular coagulation.

In summary, heparin enhances the net anticoagulant function of APC by stimulating FV inactivation. Because this occurs under heparin and APC concentrations that are physiologically and clinically well attainable, this novel anticoagulant function of heparin may well be clinically significant.

\section{Acknowledgments}

Provision of some of the reagents by Dr. Tilman Hackeng (prothrombin and purified FV) and Dr. Mary Jo Heeb (Gln506-FV and Gln506$\mathrm{FVa}$ ) is gratefully acknowledged.

This work was supported in part by grants from the National Institutes of Health (R37HL52246 and R01HL21544), the Sigrid Jusélius Foundation, the Paulo Foundation, and the Finnish Cultural Foundation.

\section{References}

1. Baruch, D., T. Lindhout, R. Wagenwoord, and H.C. Hemker. 1986. Inhibition of thrombin-catalyzed reactions in blood coagulation and platelet activation by heparin fractions in the absence of antithrombin III. Haemostasis. 16: 71-81.

2. Hirsh, J., R. Raschke, T. Wakentin, J.E. Dalen, D. Deykin, and L. Poller. 1995. Heparin. Mechanism of action, pharmacokinetics, dosing considerations, monitoring, efficacy, and safety. Chest. 108:258s-275s.

3. Sobel, M., P.M. McNeill, P.L. Carlson, J.C. Kermode, B. Adelman, R. Conroy, and D. Marques. 1991. Heparin inhibition of von Willebrand factordependent platelet function in vitro and in vivo. J. Clin. Invest. 87:1787-1793.

4. Barrow, R.T., E.T. Parker, S. Krishnaswamy, and P. Lollar. 1994. Inhibition by heparin of the human blood coagulation intrinsic pathway factor X activator. J. Biol. Chem. 269:26796-26800.

5. Barrow, R.T., J.F. Healey, and P. Lollar. 1994. Inhibition by heparin of thrombin-catalyzed activation of the factor VIII-von Willebrand factor complex. J. Biol. Chem. 269:593-598.

6. Griffin, J.H., B. Evatt, T.S. Zimmerman, A.J. Kleiss, and C. Wideman. 1981. Deficiency of protein C in congenital thrombotic disease. J. Clin. Invest. 68:1370-1373.

7. Branson, H.E., I. Katz, R. Marble, and J.H. Griffin. 1983. Inherited protein $\mathrm{C}$ deficiency and coumarin-responsive chronic relapsing purpura fulminans in a newborn infant. Lancet. ii:1165-1168.

8. Dahlbäck, B. 1995. The protein C anticoagulant system: Inherited defects as basis for venous thrombosis. Thromb. Res. 77:1-43.
9. Dahlbäck, B., M. Carlsson, and P.J. Svensson. 1993. Familial thrombophilia due to a previously unrecognized mechanism characterized by poor anticoagulant response to activated protein C. Prediction of a cofactor to activated protein C. Proc. Natl. Acad. Sci. USA. 90:1004-1008.

10. Griffin, J.H., B.L. Evatt, C. Wideman, and J.A. Fernández. 1993. Anticoagulant protein $\mathrm{C}$ pathway is defective in a majority of thrombophilic patients. Blood. 82:1989-1993.

11. Koster, T., F.R. Rosendaal, H. de Ronde, E. Briët, J.P. Vandenbroucke, and R.M. Bertina. 1993. Venous thrombosis due to poor anticoagulant response to activated protein C. Leiden thrombophilia study. Lancet. 342:1503-1506.

12. Svensson, P.J., and B. Dahlbäck. 1994. Resistance to activated protein C as a basis for venous thrombosis. N. Engl. J. Med. 330:517-522.

13. Bertina, R.M., B.P.C. Koeleman, T. Koster, F.R. Rosendaal, R.J. Dirven, H. de Ronde, P.A. Velden, and P.H. Reitsma. 1994. Mutation in blood coagulation factor $\mathrm{V}$ associated with resistance to activated protein $\mathrm{C}$. Nature (Lond.). 369:64-67.

14. Greengard, J.S., X. Sun, X. Xu, J.A. Fernández, J.H. Griffin, and B. Evatt. 1994. Activated protein C resistance caused by Arg506Gln mutation in factor Va. Lancet. 343:1361-1362.

15. Voorberg, J., J. Roelse, J.W. Koopman, H. Buller, F. Berends, J.W. ten Cate, K. Mertens, and J.A. van Mourik. 1994. Association of idiopathic venous thromboembolism with single point-mutation at $\mathrm{Arg}^{506}$ of factor V. Lancet. 343: $1535-1536$.

16. Sun, X., B. Evatt, and J.H. Griffin. 1994. Blood coagulation factor Va abnormality associated with resistance to activated protein $\mathrm{C}$ in venous thrombophilia. Blood. 83:3120-3125.

17. Dreyfus, M., J.F. Magny, F. Bridey, H.P. Schwarz, C. Planché, M. Dehan, and G. Tchernia. 1991. Treatment of homozygous protein $\mathrm{C}$ deficiency and neonatal purpura fulminans with a purified protein C concentrate. $N$. Engl. J. Med. 325:1565-1568.

18. Schramm, W., M. Spannagl, K.A. Bauer, R.D. Rosenberg, B. Birkner, Y. Linnau, and H.P. Schwarz. 1993. Treatment of coumarin-induced skin necrosis with a monoclonal antibody purified protein C concentrate. Arch. Dermatol. 129:753-756.

19. Marlar, R.A., and J.H. Griffin. 1980. Deficiency of protein C inhibitor in combined factor V/VIII deficiency disease. J. Clin. Invest. 66:1186-1189.

20. Suzuki, K., Nishioka J., Kusumoto H., and S. Hashimoto. 1984. Mechanism of inhibition of activated protein $\mathrm{C}$ by protein $\mathrm{C}$ inhibitor. J. Biochem. 95: 187-195.

21. España, F., M. Berrettini, and J.H. Griffin. 1989. Purification and characterization of plasma protein C inhibitor. Thromb. Res. 55:369-384.

22. Hirahara, K., Y. Etoh, T. Matsuishi, N. Suzuki, and M. Kurata. 1989 Synergistic effect of antithrombin III, activated protein $\mathrm{C}$ and heparin on the inhibition of the tissue thromboplastin-mediated coagulation. Chem. Pharm. Bull. 37:692-696.

23. Hackeng, T.M., C. van't Veer, J.C.M. Meijers, and B.N. Bouma. 1994 Human protein $S$ inhibits prothrombinase complex activity on endothelial cells and platelets via direct interactions with factors Va and Xa. J. Biol. Chem. 269: 21051-21058.

24. Gruber, A., L.A. Harker, S.R. Hanson, A.B. Kelly, and J.H. Griffin. 1991. Antithrombotic effects of combining activated protein C and urokinase in nonhuman primates. Circulation. 84:2454-2462.

25. Heeb, M.J., Y. Kojima, J.S. Greengard, and J.H. Griffin. 1995. Activated protein $\mathrm{C}$ resistance. Molecular mechanisms based on studies using purified Gln506-factor V. Blood. 85:3405-3411.

26. Nesheim, M.E., W.M. Canfield, W. Kisiel, and K.G. Mann. 1982. Studies of the capacity of factor Xa to protect factor Va from inactivation by activated protein C. J. Biol. Chem. 257:1443-1447.

27. Solymoss, S., M.M. Tucker, and P.B. Tracy. 1988. Kinetics of inactivation of membrane-bound factor Va by activated protein C. J. Biol. Chem. 263: 14884-14890.

28. van Putten, J.J., M. van de Ruit, M. Beunis, and H.C. Hemker. 1982. Interindividual variation in relationships between plasma heparin concentration and the results of five heparin assays. Clin. Chim. Acta. 122:261-270.

29. Hanson, S.R., J.H. Griffin, L.A. Harker, A.B. Kelly, C.T. Esmon, and A. Gruber. 1993. Antithrombotic effects of thrombin-induced activation of endogenous protein C in primates. J. Clin. Invest. 92:2003-2012.

30. Gruber, A., and J.H. Griffin. 1992. Direct detection of activated protein C in blood from human subjects. Blood. 79:2340-2348.

31. Gruber, A., A. Pal, R.G. Kiss, G. Sas, and J.H. Griffin. 1993. Generation of activated protein C during thrombolysis. Lancet. 342:1275-1276.

32. Walker, F.J. 1980. Regulation of activated protein C by a new protein. $J$. Biol. Chem. 255:5521-5524.

33. Esmon, C.T. 1992. The protein C anticoagulant pathway. Arterioscler. Thromb. 12:135-145.

34. Fulcher, C.A., J.E. Gardiner, J.H. Griffin, and T.S. Zimmerman. 1984 Proteolytic inactivation of human factor VIII procoagulant protein by activated human protein C and its analogy with factor V. Blood. 63:486-489.

35. Marlar, R.A., A.J. Kleiss, and J.H. Griffin. 1982. Mechanism of action of human activated protein $\mathrm{C}$, a thrombin-dependent anticoagulant enzyme. Blood. 59:1067-1072.

36. Fay, P.J., T.M. Smudzin, and F.J. Walker. 1991. Activated protein C-cat- 
alyzed inactivation of human factor VIII and factor VIIIa. Identification of cleavage sites and correlation of proteolysis with cofactor activity. J. Biol. Chem. 266:20139-20145.

37. Regan, L.M., L.M. O'Brien, T.L. Beattie, K. Sudhakar, F.J. Walker, and P.J. Fay. 1996. Activated protein C-catalyzed proteolysis of factor FVIIIa alters its interactions within factor Xase. J. Biol. Chem. 271:3982-3987.

38. Ofosu, F.A., M.A. Blajchman, G. Modi, A.L. Cerskus, and J. Hirsh. 1981. Activation of factor $X$ and prothrombin in antithrombin III depleted plasma. The effects of heparin. Thromb. Res. 23:331-345.

39. Schoen, P., and T. Lindhout. 1991. Flow and the inhibition of prothrombinase by antithrombin III and heparin. Blood. 78:118-124.

40. Ofosu, F.A., J.C. Lormeau, S. Craven, L. Dewar, and N. Anvari. 1994. Heparin and low molecular weight heparins inhibit prothrombinase formation but not its activity in plasma. Thromb. Haemostasis. 72:862-868.

41. Ofosu, F.A., P. Sie, G.J. Modi, F. Fernandez, M.R. Buchanan, M.A. Blajchman, B. Boneu, and J. Hirsh. 1987. The inhibition of thrombin-dependent feedback reactions is critical to the expression of anticoagulant effects of heparin. Biochem. J. 243:579-588.

42. Ofosu, F.A. 1989. Antithrombotic mechanisms of heparin and related compounds. In Heparin. Chemical and Biological Properties, Clinical Applications. D.A. Lane, and U. Lindahl, editors. CRC Press Inc., Boca Raton, FL.

43. Pieters, J., and T. Lindhout. 1988. The limited importance of factor Xa inhibition to the anticoagulant property of heparin in thromboplastin-activated plasma. Blood. 72:2048-2052.

44. Buchanan, M.R., B. Boneu, F. Ofosu, and J. Hirsh. 1985. The relative importance of thrombin inhibition and factor Xa inhibition to antithrombotic effects of heparin. Blood. 65:198-201.

45. Monkovic, D.D., and P.B. Tracy. 1990. Activation of human factor V by factor Xa and thrombin. Biochemistry. 29:1118-1128.

46. Foster, W.B., M.E. Nesheim, and K.G. Mann. 1983. The factor Xa-catalyzed activation of factor V. J. Biol. Chem. 258:13970-13977.

47. Ofosu, F.A., J. Hirsh, C.T. Esmon, G.J. Modi, L.M. Smith, N. Anvari, M.R. Buchanan, J.W. Fenton, and M.A. Blajchman. 1989. Unfractionated heparin inhibits thrombin-catalysed amplification reactions of coagulation more efficiently than those catalysed by factor Xa. Biochem. J. 257:143-150.

48. Suzuki, K., J. Stenflo, B. Dahlbäck, and B. Teodorsson. 1983. Inactivation of human coagulation factor V by activated protein C. J. Biol. Chem. 258: 1914-1920.

49. Kalafatis, M., M.D. Rand, and K.G. Mann. 1994. The mechanism of inactivation of human factor $\mathrm{V}$ and human factor $\mathrm{Va}$ by activated protein C. $J$.
Biol. Chem. 269:31869-31880.

50. Krishnaswamy, S., E.B. Williams, and K.G. Mann. 1986. The binding of activated protein C to factors V and Va. J. Biol. Chem. 261:9684-9693.

51. Deshun, L., M. Kalafatis, K.G. Mann, and G.L. Long. 1996. Comparison of activated protein $\mathrm{C} /$ protein S-mediated inactivation of human factor VIII and factor V. Blood. 87:4708-4717.

52. Kalafatis, M., P.E. Haley, D. Lu, R.M. Bertina, G.L. Long, and K.G. Mann. 1996. Proteolytic events that regulate factor V activity in whole plasma from normal and activated protein C (APC)-resistant individuals during clotting. An insight into the APC-resistance assay. Blood. 87:4695-4707.

53. Kalafatis, M., R.M. Bertina, M.D. Rand, and K.G. Mann. 1995. Characterization of the molecular defect in factor $\mathrm{V}^{\mathrm{R} 506 \mathrm{Q}}$. J. Biol. Chem. 270:40534057.

54. Keller, F.G., T.L. Ortel, M.A. Quinn-Allen, and W.H. Kane. 1995. Thrombin-catalyzed activation of human factor V. Biochemistry. 34:4118-4124.

55. Yang, X., M.A. Blajchman, S. Craven, L.M. Smith, N. Anvari, and F.A. Ofosu. 1990. Activation of factor V during intrinsic and extrinsic coagulation. Inhibition by heparin, hirudin and D-Phe-Pro-Arg- $\mathrm{CH}_{2}$ Cl. Biochem. J. 272:399406.

56. Beguin, S., T. Lindhout, and H.C. Hemker. 1988. The mode of action of heparin in plasma. Thromb. Haemostasis. 60:451-462.

57. Higgins, D.L., and K.G. Mann. 1983. The interaction of bovine factor V and factor V-derived peptides with phospholipid vesicles. J. Biol. Chem. 258: 6503-6506.

58. Sakamoto, T., H. Ogawa, H. Yasue, Y. Oda, S. Kitajima, K. Tsumoto, and H. Mizokami. 1994. Prevention of arterial reocclusion after thrombolysis with activated protein C. Comparison with heparin in a canine model of coronary artery thrombosis. Circulation. 90:427-432.

59. Kazama, Y., and T. Koide. 1992. Modulation of protein C inhibitor activity by histidine-rich glycoprotein and platelet factor 4 . Role of zinc and calcium ions in the heparin-neutralizing ability of histidine-rich glycoprotein. Thromb. Haemostasis. 67:50-55.

60. Dollery, C., I. Sullivan, O. Bauraind, C. Bull, and P.J. Milla. 1994 Thrombosis and embolism in long-term central venous access for parenteral nutrition. Lancet. 344:1043-1045.

61. Woodman, R.C., and L.A. Harker. 1990. Bleeding complications associated with cardiopulmonary bypass. Blood. 76:1680-1697.

62. Petäjä, J., K. Peltola, H. Sairanen, M. Leijala, R. Kekomäki, E. Vahtera, and M.A. Siimes. 1996. Fibrinolysis, antithrombin III and protein C in neonates during open heart surgery. J. Thoracic Cardiovasc. Surg. 112:665-671. 